\title{
Structural and optical properties of an undoped and Mn doped ZnO nanocrysatlline thin film
}

\author{
M. Nirmala, A. Anukaliani* \\ PG and Research Department of Physics, Kongunadu Arts and Science College, \\ Coimbatore - 641 029, Tamil Nadu, India.
}

Received September 30, 2010; accepted December 27, 2010; published December 31, 2010

\begin{abstract}
In this study a $\mathrm{ZnO}: \mathrm{Mn}$ nano structured film doped with manganese of different concentrations is deposited on glass substrates by the sol-gel dip coating method. Characterization techniques of XRD, SEM with EDAX and UV-Visible spectra measurements were done to investigate the effect of an Mn doping concentration on the optical and structural properties of a $\mathrm{ZnO}: \mathrm{Mn}$ nanostructured thin film. XRD patterns of all nanostructured thin film show crystallization behavior and have a hexagonal wurtzite structure. Optical studies show that the band gap of $\mathrm{ZnO}: \mathrm{Mn}$ decreases because of the $\mathrm{d}$ electron of $\mathrm{Mn}$ atom and band carriers of the host material.
\end{abstract}

$\mathrm{ZnO}$ is a II-IV semiconductor compound and has a direct bandgap around $3.2-3.37 \mathrm{eV}$ in $300 \mathrm{~K}$ with a high exciton binding energy of $60 \mathrm{meV}$ and is a wide bandgap semiconductor. $\mathrm{ZnO}$ thin films are important materials [1], due to their unique properties such as low electric resistance, high transparency in the visible light, piezoelectricity, high voltage-current nonlinearity and chemical stability [2] and their applications are in bulk acoustic wave solar cells, transparent electrodes, blue UV light emitter device and gas sensors [3]-[8]. Many techniques used to deposit a high quality $\mathrm{ZnO}$ thin film and nanofilm are rf or dc sputtering, pulsed laser deposition (PLD), ion plating, chemical vapour deposition (CVD), thermal evaporation, spray pyrolysis and molecular beam epitaxy (MBE). A chemical method is widely used in the synthesis of a $\mathrm{ZnO}$ nanocrystal and also the sol-gel process [12], being simple, inexpensive in fabrication of a large number of samples, easier for composition control, with accurately controlled mole ratio, high solubility, better homogeneity, and lower processing temperature and a general advantage of large area deposition and any suitable thickness of the film.

The precursors utilized for the synthesis of $\mathrm{ZnO}: \mathrm{Mn}$ are: Zinc acetate dehydrate $\left[\begin{array}{lll}\mathrm{Zn}\left(\mathrm{CH}_{3}\right. & \mathrm{COO})_{2} & 2 \mathrm{H}_{2} \mathrm{O}\end{array}\right]$, manganese acetate tetrahydrate $\left[\mathrm{Mn}\left(\mathrm{CH}_{3} \mathrm{COO}\right)_{2} 4 \mathrm{H}_{2} \mathrm{O}\right]$ as a zinc and manganese source, 2-methoxyethanol (DME) $\left[\mathrm{C}_{3} \mathrm{H}_{8} \mathrm{O}_{2}\right]$ and monoethanolamine (MEA) $\left[\mathrm{C}_{2}\right.$ $\left.\mathrm{H}_{7} \mathrm{NO}\right]$ as a solvent and a stabilizer, respectively.

*E-mail: anuplasmakasc@gmail.com
All chemicals were purchased from Merck Company. All samples of a $\mathrm{ZnO}: \mathrm{Mn}$ nano structured thin film were prepared by the sol-gel method.

First, at room temperature, zinc acetate and a dopant were dissolved in a mixture of the DME and MEA solution. The molar ratio of MEA to $\mathrm{Zn}^{+2}$ was maintained at 1 . Solutions were prepared containing zinc acetate, manganese acetate of 10, 12 and 14 at \% DME and MEA. At $70^{\circ} \mathrm{C}$, the solution was vigorously stirred for $1 \mathrm{~h}$ by means of a magnetic stirrer to yield a clear and homogeneous solution. At room temperature, the coating solutions were aged for at least one day, and then deposited on glass slide substrates, which had been cleaned previously by dip coating. An undoped $\mathrm{ZnO}$ precursor was prepared in the same way. The glass slide was dipped in a sol solution for 5 minutes, and then the film was preheated at $150^{\circ} \mathrm{C}$ for 15 minutes to evaporate the solvent and organic residuals. The procedure was repeated 5 to 8 times to reach the desired thickness. The film was then post heated at $300^{\circ} \mathrm{C}$ for $1 \mathrm{hr}$. Characterization of the samples was performed in room temperature.

An X-ray diffractometer (XRD 6000, Shimadzu, Japan) with $\alpha \mathrm{CuK}$ line radiation $(\lambda=1.5406 \AA)$ was used to determine the crystallite phase and orientation. Figures 1 a-d show XRD-ray patterns of all samples which were deposited on glass substrates. The diffraction patterns reveal good crystalline quality without any appreciable changes from pure $\mathrm{ZnO}$ films and are genuinely polycrystalline with a hexagonal wurtzite structure. These results imply that there are no secondary phases such as a manganese cluster or oxides. The average size of the undoped $\mathrm{ZnO}$ is found to be $40 \mathrm{~nm}$, and for 10, 12 and 14 at $\% \mathrm{Mn}$ doped $\mathrm{ZnO}$ the average size is found to be 37, 34 and $29 \mathrm{~nm}$, respectively. The wide distribution of grain size of samples on the film can be the possible reason resulting in broadening the diffraction peaks. This may be due to the ionic radius of $\mathrm{Mn}^{2+}(0.83 \AA)$ that is larger than the ionic radius of $\mathrm{Zn}^{2+}(0.74 \AA)$. This phenomenon in the films creates strain or stress because of mismatching $\mathrm{Mn}^{2+}$ in the $\mathrm{Zn}^{+2}$ lattice site. However, the crystal quality of films decreases with an increase in the Mn percentage [13]. 

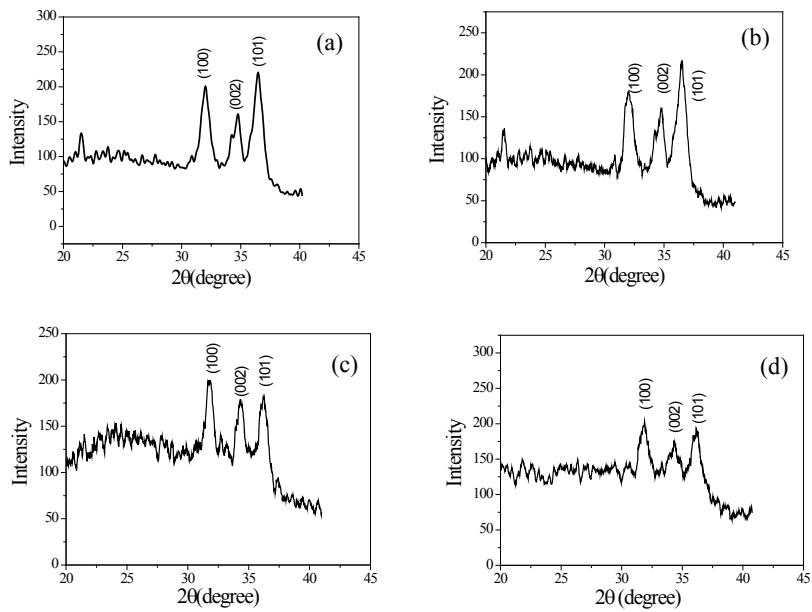

Fig. 1. XRD patterns of $\mathrm{ZnO}$ (a), $\mathrm{ZnMn}_{0.10} \mathrm{O}$ (b), $\mathrm{ZnMn}_{0.12} \mathrm{O}$ (c) and $\mathrm{ZnMn}_{0.14} \mathrm{O}(\mathrm{d})$.

Surface morphological studies of undoped and manganese doped $\mathrm{ZnO}$ films have been carried out using a scanning electron microscope. Figures 2 a-d show SEM images of an undoped and $\mathrm{Mn}$ doped $\mathrm{ZnO}$ film. The SEM images of $\mathrm{ZnO}$ resemble a granular surface. The incorporation of Mn ions changed surface morphology to a wrinkle network. The crystalline nature of films was affected due to the enhancement of dopant concentration, by which more impurities were included in the $\mathrm{ZnO}$ crystal. For an Mn concentration of 12 at \% the morphology of the film was neither wrinkle nor whiskers and for 14 at \% of Mn concentration the morphology of the film changed to whiskers [14]-[15]. (a)

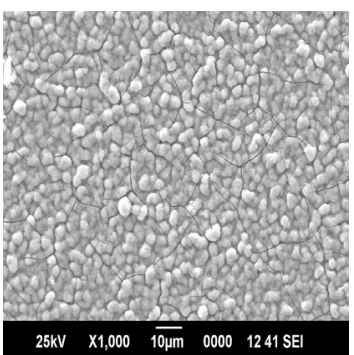

(c)

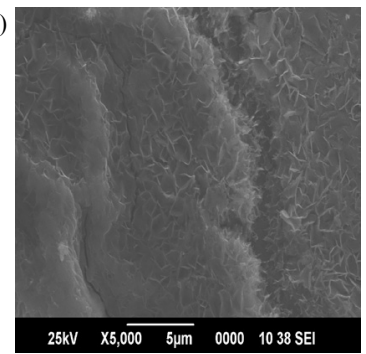

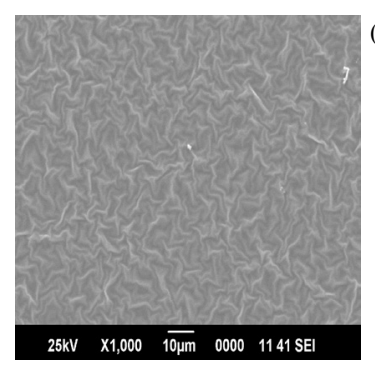

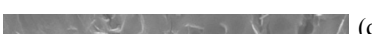
(b) (d)

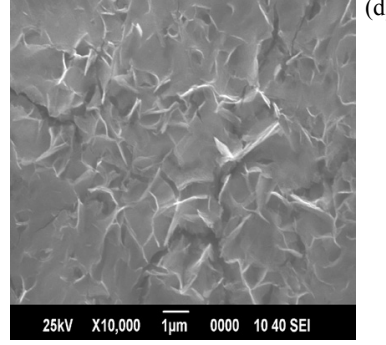

Fig. 2. SEM images of $\mathrm{ZnO}$ (a), $\mathrm{ZnMn}_{0.10} \mathrm{O}$ (b), $\mathrm{ZnMn}_{0.12} \mathrm{O}$ (c) and $\mathrm{ZnMn}_{0.14} \mathrm{O}(\mathrm{d})$
For determining the composites in a different doping Mn concentration of a $\mathrm{ZnO}: \mathrm{Mn}$ nano film, compositional analysis was performed by Philips XL 20 energy dispersive X-ray (EDX) analysis. The EDX analysis showed that the amount of an Mn element in the sample increased depending on increased $\mathrm{Mn}$ incorporation in the solution. As a result, the Mn incorporation has a strong effect on the optical, structural and morphological properties of $\mathrm{ZnO}$.

Table.1. Band gap energy

\begin{tabular}{|c|c|}
\hline Dopant concentration in ZnO & $\begin{array}{c}\text { Band gap Energy } \\
\left(\mathbf{E}_{\mathbf{g}}\right)[\mathbf{e V}]\end{array}$ \\
\hline 0 at $\%$ & 3.27 \\
\hline 10 at $\%$ & 3.26 \\
\hline 12 at $\%$ & 3.24 \\
\hline 14 at $\%$ & 3.20 \\
\hline
\end{tabular}

The optical properties of the films were studied from the transmittance spectra shown in Fig.3. With increase of $0,10,12,14$ at \% manganese concentration, the optical transmittance spectra of the samples gradually increase in the visible region. The optical energy band gap shows a blue shift with increasing Mn doping concentrations. The optical band gaps have been calculated from the transmittance spectra and estimated by extrapolation of the linear relationship,

$$
(\alpha h v)^{2}=h v-E_{g}
$$

Where $\alpha$ is the absorption coefficient, $h v$ is the photon energy, $E_{g}$ is the optical band gap of a nanofilm which is determined by the theory of direct optical absorption. Figure 4 shows the $(\alpha h v)^{2}$ vs. photon energy curves of a $\mathrm{ZnO}$ nanofilm with a varying doping concentration (see Table 1). The band gap value decreases with an increased Mn doping concentration which may due to the sp-d exchange interactions and has been theoretically explained using the second-order perturbation theory [16]-[17].

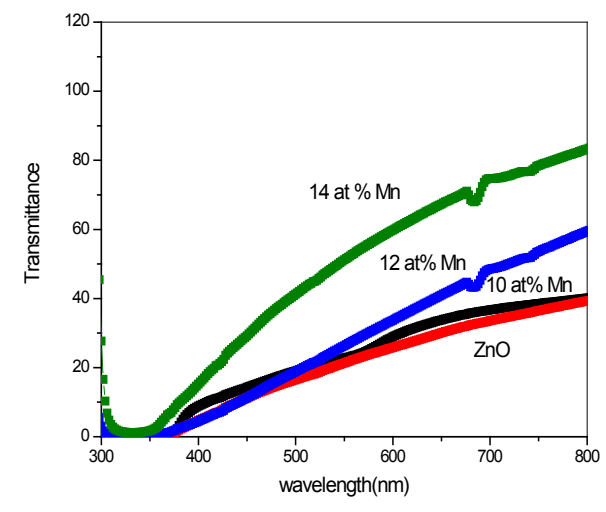

Fig.3. Transmittance spectra of $\mathrm{ZnMnO}$. 


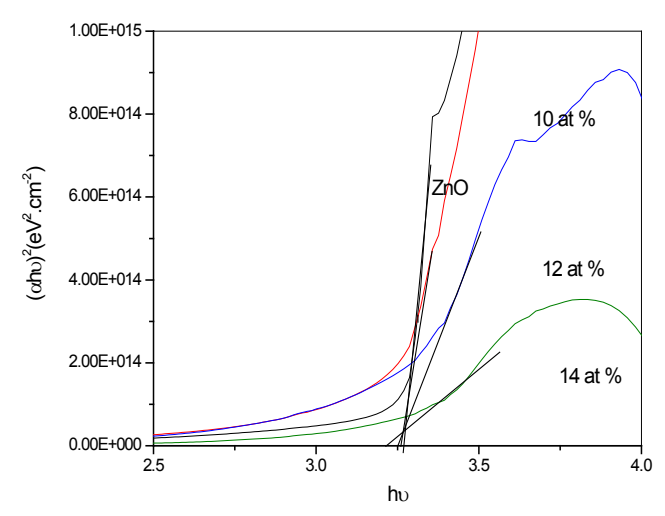

Fig. 4. Optical band gap of $\mathrm{ZnMnO}$.

In conclusion, transparent nanostructured undoped and $\mathrm{Mn}$ doped $\mathrm{ZnO}$ thin films on glass substrates were prepared by a sol-gel method using a dip-coating method. The films produced by a sol-gel method were found to be highly c-axis oriented and the transmittance was increased in the visible region with increase of manganese. The present work represents a better method for synthesizing $\mathrm{ZnO}$ nanosized crystals using stable solutions with few additives and then forming homogeneous layers on glass substrates. The thin films were characterized by XRD, SEM and ultraviolet-visible spectrophotometry, which indicate that solgel $\mathrm{ZnO}$ films have potential applications such as catalyst and transparent electrodes in optoelectronic devices.

\section{References}

[1] K. Keis, C. Bauer, G. Boschloo et al., J. Photochem. Photobiol A 148, 57 (2002).

[2] D.C. Look, Mater. Sci. Eng B 80, 383 (2001).

[3] C. Lee, K.J. Lim, K. Song, Sol. Energy Mater. Sol.Cells 43, 37 (1996).

[4] T. Negami, Y. Hashimoto, S. Nishiwaki, Sol. Energy Mater. Sol.Cells 67, 331 (2001).

[5] Y. Natsume, Thin Solid Films 372, 30 (2000).

[6] G.K. Paul, S. Bandyapadhyay, S.K. Sen, Phys. Stat. Sol A 191, 509 (2002).

[7] D.C. Look, D.C. Reynolds, C.W. Litton et al., Appl. Phys. Lett. 81,1830 (2002).

[8] X. Wang, W.P. Careg, S. Yee, Sensors Actuators B 28, 63 (1995).

[9] B. Kulyk, V. Kapustianyk, V. Tsybulsky, O. Krupka, B. Sahraoui, J. Alloys Compd. 502, 24 (2010).

[10] Z. Sofiani, B. Sahraoui, M. Addou, R. Adhiri, M. Alaoui, B. Derkowska, W. Bala, J. Appl. Phys. 101(6), 063104 (2007).

[11] Z. Sofiani, B. Derkowska, P. Dalasinski, M. Wojdyla, S. DabosSeignon, M. Alaoui Lamrani, L. Dghoughi, W. Bala, M. Addou, B.Sahraoui, Opt. Com. 267(2), 433 (2006).

[12] P. Sagar, M. Kumar, R.M. Mehra, Thin Solid Films 486, 94 (2005).

[13] J.H. Lee, B.O. Park, Thin Solid Films 426, 94 (2003).

[14] M.H. Habibi, M. Khaledi Sardashti, J.Iron.Chem.Soc 4, 603 (2008)

[15] G. Srinivasan, J. Kumar, J. Crystal Growth 310, 1841 (2008).

[16] P. Singh, A. Kaushal, D. Kaur, J. Alloys and Compounds 471, 11 (2009).

[17] R.B. Bylsma, W.M. Becker, J. Kossut, U. Debsta, Phys Rev B 33, 8207 (1986). 